\title{
Promoting Citizen Participation through Television Drama Series: A Case of Makutano Junction Viewership among Pioneer Location Residents in Kenya Zipporah Koroti ${ }^{1 *}$
}

${ }^{1}$ Department of Publishing, Journalism and Communication Studies, Moi University P.O. Box 3900-30100, Eldoret

DOI: $10.36347 /$ sjahss.2021.v09i04.002

| Received: 09.02.2021 | Accepted: 30.03.2021 | Published: 18.04.2021

*Corresponding author: Zipporah Koroti

\section{Abstract}

Makutano Junction $(M J)$ is a serial television drama that uses Entertainment Education (EE) as a communication strategy to inform viewers about citizen participation, political and socio-economic development issues. In this paper, reference is made to Season Eleven of Makutano Junction with an aim to determine how MJ plotlines promoted audience participation among citizens. Season Eleven of $M J$ was aired in the year 2011 with the aim of educating citizens on their rights and responsibilities as enshrined in the governing Constitution of Kenya, 2010. The study, guided by the Social Learning theory elucidated audience involvement with $M J$. The study adopted a sequential mixed-method employing both quantitative and qualitative research approaches to data collection. The target population comprised 250 viewers of the drama series in Pioneer Location, Uasin Gishu, Kenya from which a sample size of 57 active viewers were purposively selected. Data analysis was done by way of thematic analysis forming a basis for discussion of emerging themes. This study established that there were desirable changes in knowledge and attitudes of audiences who viewed $M J$ hence the social set up and social roles affect the selection, uses and effects of media content by the audience. The study also recommends that EE message designers should understand the effect that such programmes have on the viewers and take advantage of digital explosion and broadband services to produce diverse media formats and content for a wider reach.

Keywords: Social, Economic, $M J$ Plotlines, Entertainment Education, Communication, Participation, Citizens.

Copyright $\odot 2021$ The Author(s): This is an open-access article distributed under the terms of the Creative Commons Attribution 4.0 International License (CC BY-NC 4.0) which permits unrestricted use, distribution, and reproduction in any medium for non-commercial use provided the original author and source are credited.

\section{INTRODUCTION}

The concept of 'citizenship' has been described by scholars such as Maslamani [1] and Mwangi [2], to imply a symbolic reality of equal treatment hence a concept in measuring individual rights and obligations [3]. Citizenship can be derived in various perspectives - civic citizenship and state citizenship [3]. Social citizenship is drawn from political and doctrinal dominance of the right to welfare, state benefits and the right to greater equality of citizens. Citizenship is also seen as a civic identity resulting from multicultural demographic composition in states arising from migrants and politicized awareness within the states. It is related to one belonging to a particular state e.g. a Kenyan citizen, Israeli citizen [3]. This study is confined to social citizenship whose benefits concern the quality of life provided for by government to improve the wellbeing of their people and equal participation. Heather [3] opines that focus on 'good citizenship' is concerned with knowing individual rights and volunteering for activities, rationally evaluating factual information and being close to others on an emotional level [3, 4]. In essence, this study considers a citizen as a member of a community who participates in the community activities and enjoys the histories, cultures and public utilities as well as features in a given locality. A good citizen is an active participant who is motivated to learn more about issues and does something to solve a pressing problem as an individual or in a group [5]. When citizens become active participants in rights issues, social scientists get concerned with measuring the levels, causes and consequences of their participation [3]. Citizen participation helps create and strengthen citizens themselves, increasing their feelings of political efficacy and knowledge. This in turn, benefits the larger society in the achievement of development goals and propagating citizens' rights into a reality $[6,7]$.

The $M J$ programme was first aired on $\mathrm{KBC}$ Television but in 2009. The programme was aired from 7:30pm to 8:00pm every Wednesday (Currently it is off air) a time considered to be prime since there was maximum viewership [8]. During this time (in 2001- 
2013) when $M J$ was on air, Kenya was in a moment of profound political, social and economical problems. The period was characterised by high-level sleaze, corruption and mistrust in the economic and political landscape. According to Transparency International (TI) Corruption Perception Index 2011, Kenya was ranked 154 out of the 182 countries surveyed on corruption. The Grand Coalition Government zerotolerance policy on corruption had only improved marginally by scoring 2.2 per cent compared to 2.1 per cent in 2010 [9].

As the government of Kenya continued to grapple with the challenges of corruption, unemployment, high rates of crime, unequal distribution of resources, tribalism, discrimination, poverty and poor quality of education, the economic and social power of citizens is largely undermined. More so, the $38.5 \%$ illiteracy levels in Kenya locks out most citizens in understanding the legal jargon of the Constitution, other laws and policies to enable them become aware of their rights so as to effectively participate in national development $[10,11]$. Mass media, radio and television in particular have therefore become the best tool of educating as many citizens as possible on their rights and responsibilities especially through drama which uses culturally and linguistically adaptive messages that resonates well with the audience. This tool as observed in research fosters public debates and promotes behavioural change on matters of development [12-14]. This paper therefore conducts an analysis of the programming of $\mathrm{MJ}$ plotlines to enhance citizen participation in development.

\section{Makutano Junction - A Brief Look}

In 2001, a popular drama Series Makutano Junction (MJ) sponsored by the Department for International Development (DFID) and supported by Ford Foundation was introduced in Kenya by the Mediae Company to inform citizens about their legal and human rights, government policies and development issues. The producer conveyed these issues in simple storylines using the Entertainment Education strategy in the $M J$ drama whose setting is peri-urban in order to capture the attention of the viewers and foster public debates that can bring about positive social change in order to empower citizens for development (David Campell, Executive producer). This section provides a review of the MJ series plotlines to create an understanding of how these plotlines engage with society in general.

Season Eleven of Makutano Junction is embedded with information that raises awareness on education quality, healthcare delivery, corruption, irresponsible leadership and impunity. All these issues encompassed in ten episodes of Season Eleven, were geared towards encouraging citizens to take charge, engage with the processes and demand for better services [15].
Episode 1 focused on the issue of achieving quality education by sharing responsibilities between parents, teachers and the community. Bernadette represents a mobilizer who influences the community to take a particular direction. She stands her ground that she does not want Stellah the new teacher to be admitted in Makutano Junction primary school because of her 'poor grade'. Most parents supported her at first but later realized that some teachers had the same grade like Stellah's thus they were to lose all teachers if they followed Bernadette's reasoning. After discussing, the community found out that the problem was with the education system. They resolved to work together with teachers and the board of management for the benefit of their children. This is aimed at teaching the citizens or viewers on the importance of Collective responsibility. In the same episode, the nurse at a public hospital cooperated with Washington; the private pharmacists to steal repackage and sell government procured drugs. A lesson to the society is that individuals should take personal responsibility in taking care of community resources and ensure proper use for sustainability.

In Episodes 2, teacher Dranny represents teachers who abscond duty to engage in personal businesses. Dranny secretively leaves the class to do business and when the head teacher Ms. Pendo discovers that he is not around; she looks for him and finds him painting shops in the market centre. Dranny then exposes other teachers who also abscond duty. The meeting between pupils, teachers and parents resolve for accountability and responsibility by each party in order to achieve the best for the pupils.

Episode 3, Joseph represents leaders who practice impunity through their influential position in the community. Joseph gives Josiah his relative a responsibility to manage water supply project though he lacks qualification and experience. Joseph exercises nepotism for his own gain by misusing Josiah to engage in corrupt deals with a private flower farm to supply water illegally at a fee which is later channelled to Joseph. Florence and her co-host misuse the community radio station by airing irrelevant stories; this causes the community to storm the radio station demanding for their eviction, Pipi on the other hand intervenes by offering his technical skills to assist Florence learn how to use Google to search for relevant topics that will benefit the community. People become happy and interested when they are engaged in the radio programmes through mail, short message service (SMS) and call-ins to discuss development issues.

Snake and Josiah represent crooked individuals in society who punish the community to gain what they want. The two embark on a strategy of diverting water from people's taps to run dry so that they can sell the water at exorbitant prices. In episode 4, the issue of poor health services offered in public 
hospitals comes up. Dr. Penny pulls aside patients from long queues to her office and asks them for a bribe for her to attend to them faster. She portrays the picture of incompetence when she misdiagnoses Bernadette. She also moves around commanding and abusing nurses while her colleague Dr. Charles is overwhelmed by long queues of patients. Apparently, every patient shuns Dr. Penny for her incompetency and prefers to see Dr. Charles.

Mr. Mabuki, Mrs. Matata and Joseph all being board members of the dispensary, plot to use Constituency Development Fund (CDF) money to construct another medical facility through their construction company but a frustrated Dr. Charles puts them off by pointing out the issue of staffing and drug supply to be attended to first and not constructing another facility. Dr. Charles advices Bernadette, her husband; Mr Baraka and Mr Mabuki to file complaints with Kenya Medical Practitioners and Dentist Board and Health Rights Advocacy Forum concerning Dr. Penny's misdiagnosis. Later on Dr. Charles tones down and tells them the matter is being solved internally after being threatened by Dr. Penny out of her impunity.

In episode 5, Pipi, Baraka's son who is a technological expert explains to his father's friends how technology has made it easy to get government services online and made government information more available, he shows them how to use the e-citizen portal to transact anything with government.

In episodes 6 and 7, it is messy all over due to disconnection of water by Snake and Josiah. Makutano Junction experiences smelly public toilets, dirty hotels, schools and streets, diarrhoea breaks out while Karis takes advantage of the situation to sell fake distilled water. Mabuki being the school Chairman gives his son Karis a tender to renovate school toilets. Karis takes advantage of the situation and convinces the bank to sponsor the project and consumes the ministry's money set aside for the project. The bank manager; Mr. Shaka discovers he was short-changed by Karis when he attends the toilet opening ceremony and his bank is not recognized as one of the sponsors of the project. The situation of drug shortages at the hospital worsens. Dr. Penny keeps on referring patients to buy drugs at Washington's pharmacy where she stocks drugs for business. Margret represents desperate patients whose lives are hanging on the string for lack of life sustaining anti retrovirals (ARVs). Penny refers her to Washington or to look for ARVs in the streets if she doesn't have money.

In Episode 8, the residents of Makutano Junction become impatient with prolonged shortage of water hence protest for their right to water. The Chief investigates and finds out that water had been diverted by Snake and Josiah and asks them to reinstate water to the community. The community resolves to work together by ensuring their water is not interfered with.

In episode 9 Shaka notices teacher Dranny wooing a female pupil, he reports the matter to the head teacher who disputes the allegation in support of the immoral teacher. Dranny orders Beatrice the female pupil to take books to his house and in turn molests her. Shaka meets with Beatrice crying and takes her to hospital for extermination. Dranny is implicated for rape but becomes defensive and beats up Shaka until he is injured. Beatrice's parents and the Head teacher admit negligence on the matter and discover that the school lacked regulations and laws on child protection; they resolve to do the regulations.

In episode 10, Washington and Penny's scam with health centre drug puts people's lives in danger. Margret's condition worsens after skipping ARVs while many patients lose their lives. The chief discovers the drug scam and reports the matter to the health centre's committee. The committee resolves that accountability on use of drugs should be observed, complaints service be set up, patients be sensitized on use of 'huduma' SMs 3108 to report complaints and receive feedback from government.

\section{MATERIALS AND METHODS}

This paper premises the discussion of $M J$ on the social learning theory. The social learning theory explains how by observing others, audience can learn, be motivated to change, and believe that they can change. Seeing how the characters in the drama solve problems can give audiences the sense that they too, can control their lives and solve problems affecting them (self-efficacy) or succeed like the characters in a story either as individuals or as a community [16]. Learning is a continuous process and is expected to impact or change in behaviour of the learners. According to Weinstein and Mayer [17] as cited in Nabavi [18], learning implies "the relatively permanent change in a person's knowledge or behavior as a result of experience" (p.4). As adopted in this paper, the Social Learning theory depicts a change in behaviour among the viewers whereby it is hoped that they learn from the drama series so as to impact on their own life. Green and Peil 2009 argue that social cognitive theory broadly explains socialization, as a procedure through which individuals acquire societal norms of thought and action.

The study was carried out in Pioneer location of Uasin Gishu County exploring the response of the audience to $M J$ serial drama produced in Kenya and the audiences' eventual participation based on the lessons learned. This study adopted a quan $>$ QUAL sequential mixed method design, in which a qualitative approach dominates the study whereas the quantitative approach produces the sample from which the sub groups are selected for further intensive study (qualitative 
approach) $[19,20]$. This study adopted Creswell's [21] participant selection model of sequential explanatory design as indicated in Figure 1.

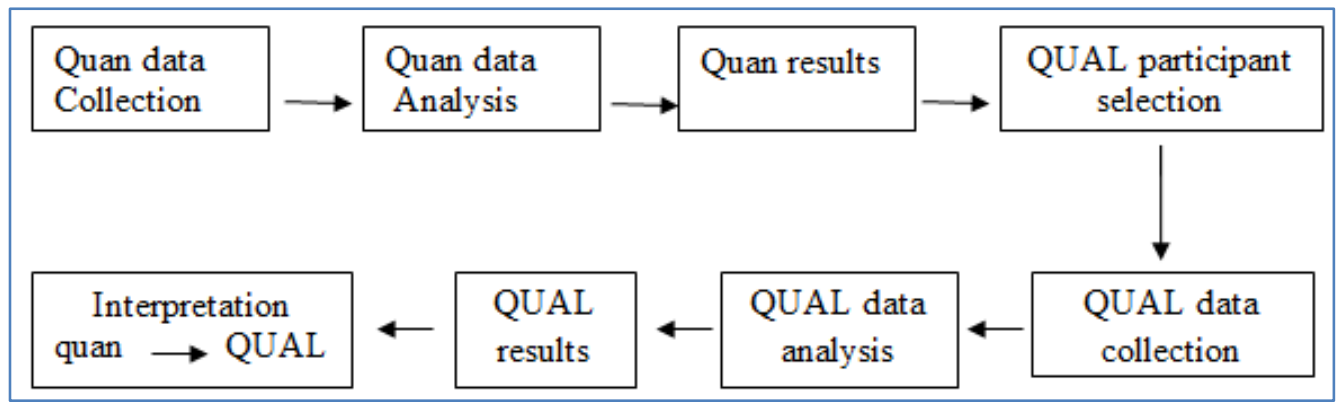

Fig-1: Sequential Explanatory Design Participant Selection Model

Source: Adapted from Creswell (2006)

Quantitative phase involves a quantitative data collection and analysis, and thereafter the quantitative results are used to produce a sample for qualitative data collection and analysis. The two methods combined at the interpretation stage with the qualitative interpretations dominating the results interpretation [21].

Potential viewers of Makutano Junction serial drama were identified at the quantitative phase from which insights on viewership interests were gathered to help examine how the same influenced their participation. In particular, the study used crosssectional survey design [22] and self-administered questionnaire guide that included both closed and openended questions. A total of 352 questionnaires were distributed in 8 administrative blocks within Pioneer location. The blocks included Langas, Pioneer, Kipkaren, Kipkenyo/Cherunya, Elgon View, Sukunanga, Racecourse and Yamumbi. The study sample size was reached at using Slovin's fomula [23].

\section{Slovin's Formula}

$\mathrm{n}=\mathrm{N} /\left(1+\mathrm{N} \mathrm{e}^{2}\right)$

Where, $\quad \mathrm{n}$ - Sample size; N - Researchable population for the households; e - Error tolerance; and n = 2,924/ $\left(1+2,924 * 0.05^{2}\right)$

$=351.87$ rounding the answer to a whole number (because you can't sample a fraction of a person or a thing) $=352$

In addition, focus group discussions were conducted for in-depth interviews in order to answer the "how" question of citizen participation based on the drama series plotlines. Sood [24] and Dyll-Myklebus 2013, argue that audience involvement with drama texts can be better understood by asking questions about how audiences make sense out of EE media messages rather than fitting audience responses into preconceived reception categories. Nevertheless, in-depth interviews were used to obtain information from key informants who were consistent viewers and informed opinion leaders in the society who can influence the community.

Descriptive data analysis was then employed where the distribution of variables were explored using tables. Frequencies of variables and differences between the variables were calculated then objectively interpreted the results through comparing the findings.
Narrative analysis was also performed on textual accounts of interviews and observation raised.

\section{RESULTS AND DISCUSSION}

For the purpose of understanding clearly how Entertainment Education and audience use are related, the author went ahead to find out the level of respondent participation in the programme. The collected data indicated that very few respondents participated in asking questions and taking part in the programmes completion. This meant that most of the respondent's participation stopped at watching the programme. Those who watched the programme even without participation highlighted the following informative issues that they learnt from the programme as shown in Table1. 
Table-1: Informative Issues Learnt from the Programme

\begin{tabular}{|l|l|l|l|}
\hline Response & Frequency & Percentage & Cumulative Percentage \\
\hline Learnt about corruption issues & 36 & $34.86 \%$ & $34.86 \%$ \\
\hline Learnt about social development issues & 9 & $9.14 \%$ & $44 \%$ \\
\hline Savings as a lifestyle & 15 & $14.86 \%$ & $58.86 \%$ \\
\hline Women empowerment & 12 & $12 \%$ & $70.86 \%$ \\
\hline Political respect & 9 & $8.57 \%$ & $79.43 \%$ \\
\hline Community decision making & 11 & $10.86 \%$ & $90.29 \%$ \\
\hline Hard work pays & 10 & $9.71 \%$ & $100 \%$ \\
\hline Total & $\mathbf{1 0 2}$ & $\mathbf{1 0 0 \%}$ & \\
\hline
\end{tabular}

Data from Table 1 above illustrates that the informative issues learnt by the viewers of the drama are issues about corruption which attracted the highest response rate at $36(34.86 \%)$ of the total respondents who said that they had watched this program. Saving as a lifestyle is another issue learnt by 15 (14.86\%) of the total respondents, women empowerment attracted a response rate of $12(12 \%)$, Community decision making $11(10.86 \%)$, Hard work pays, $10(9.71 \%)$.
The study finding ascertained that 102 respondents had watched Makutano Junction serial drama with varying reasons that impelled them to watch and also they could recall all or a bit of the programme content. There were many reasons for watching the programme and lessons learned however, the author purposively selected the respondents who indicated the following reasons that have a learning aspect:

Table-2: Responses with Learning Aspect

\begin{tabular}{|l|l|l|}
\hline Reasons for Watching $\boldsymbol{M J}$ & Frequency & Percentage \\
\hline To learn & 20 & $35.1 \%$ \\
\hline To ask questions & 9 & $15.8 \%$ \\
\hline To participate in the competition & 7 & $12.3 \%$ \\
\hline To share with others & 14 & $24.6 \%$ \\
\hline For studies & 7 & $12.2 \%$ \\
\hline Total & $\mathbf{5 7}$ & $\mathbf{1 0 0 \%}$ \\
\hline
\end{tabular}

The respondents commented on the drama as a whole in reference to the characters' behaviour, actions and their personalities. The audience also cited strengths and weaknesses of Makutano Junction drama and made remarks on the realities and plausibility of the stories in Season Eleven of the drama.

Both the focus group and the in-depth interview respondents found the drama to be effective in addressing issues of citizen participation. For instance, Nick (not his real name) an in-depth interview respondent who was a 36-year-old graduate serving as a manager and trainer in a college, acknowledged that the programme had effectively addressed issues of citizen participation through imparting knowledge to viewers.

Makutano Junction is an educative programme, it teaches people to understand, it gives information, enlighten them, and empowers them......for any community to be active, it has to be knowledgeable.........the aspect of citizens participating in those things that directly affect them, they also have to be interested to know how those things are happening, how the hospital is being run, how a school is being run, how churches are being run. Anything that is public; they need to actually participate and be very serious in an active manner. Just like what $I$ see in
Makutano Junction (Nick, personal communication, 2013).

Nick's observation is supported by participant number 3 (a 28-year-old business lady) of the focus group discussion (FGD) who observed that citizen participation is a solution-based approach that the drama has illustrated very well:

As for me, I can see there is public participation because looking at the first episode which involved the teacher, the community came in when the teacher was being rejected by some parents and they were able to address the issue and teacher Stellah was able to be accepted finally (FGD, participant No. 3).

Nick however pointed out that the programme might not have been effective in reaching many people because he foresaw a situation where people were missing out on the programme because they had not been enlightened on the importance of such an educative programme for them to consciously choose to sit down and watch it with an understanding.

nobody has actually been enlightened that it is a good programme to watch and maybe it could help in solving some of the 
problems in which I am part of. If there is a problem for example a water problem I am part of it (Nick, personal communication, 2013)..

By citing several examples from the drama participants generally observed that the stories are real and believable because they replicate their environment. Most of these stories are negative and revolves around corruption, reluctance, irresponsibility and selfishness centeredness.

Participants were divided on the way the drama portrayed the issue of community participation. A few participants said that Makutano Junction community was not cohesive while a majority applauded the community for working together to arrest the arising situations.

I am happy with the community because anything that was related to corruption they came together and talked and finally came up with a solution (FGD participant 2: a 21-yearold university student).

As for me, I have been attracted by the cooperation of the community, especially when they called each other and came together to solve the school toilet problem. This shows how the Makutano community is very concerned with their children welfare (FGD participant 5: a 30-year-old housewife).

The participants viewed the drama critically terming it as a drama of its own kind because it is real and not 'fiction,' for instance Lorah (a 50-year-old secondary school teacher and a woman leader, a mother of four and a pastor) cites the burden that health workers in Kenyan hospitals have and noted which relates to the $M J$ plotline:

The struggles with work at the hospital, it is so rampant right now [in public hospitals] until the workers are discouraged; so that they just give up on their work. And harassment by bosses like Penny............ I don't know she is not even true to herself because she is saying that the client comes first, is that what she is doing herself when she is not even serving Kenyans? We have leaders' who preach water and take wine (Laura, personal communication, 2013).

The participants acknowledged that the summary which is given at the end of the programme encourages viewers to make follow-up if they need more information. However, the participants also pointed out some of the weakness in the programme including the time slot that was allocated to airing the programme as not being accommodative. They also noted that too many issues are tackled in one episode which is about twenty minutes only.

........as much as they (producer) want to create suspense you may not be able to fully articulate a particular subject and if you script something an episode should be continuous and not tackling to many things in the same programme (meant episode) at the same time; you are dealing with water, you are dealing with education, you want to deal with pharmacy for example (Tony 30-year-old in depth-interview participant working as a management consultant and a personal development trainer).

Some participants noted that there is a tendency of the programme not showing the root causes of some of the problems rather superficial information is given. Moreover, the solutions to some of the problem are so narrow and poor interpreters may not decipher the producers' intentions by virtually interpreting the actors' behaviours and actions.

Some of those things you [referring to the producer] don't show the root cause you only show what is happening superficially that may not give people exactly what would help them maybe to change (Nick, personal communication, 2013).

The FGD participant number 4 (a 42-year-old woman working in a restaurant) commenting on weakness said that she has a problem with the use of English language and instead advocates for use of Kiswahili which everyone understands including children who also need to be educated.

However, Emmah (a 52-year-old church leader and head of department in the Government ministry) in an in-depth interview noted that she believes the mixing of language whereby the youth speak sheng and old people speak simple English reflects what happens in the community and there is neither misunderstanding nor miscommunication. Emmah believes the community has been well targeted by the language register that is familiar to the Kenyan setting.

The inconsistencies in airing the programme was a major concern by the respondents who said the programme is always off air for some time and by it taking time before it resumes it ends up losing fans. As much as many participants acknowledged that the programme was credible they wished that the producer should in future be practical enough by involving people on the ground during the shooting stage to draw actors from the community where acting is taking place. that will make it even more exciting and viewers will even feel..., you know that 
touch, that connection

(Tony, personal communication, 2013)

Nick also said that the programme is of great importance to him and it has really helped him in his day to day activities and according to him the programme is real. He reported:

I think my experiences were the sharing, if I watch a nice thing which I think is good for somebody else I talk about it in many forums and being in my position I would give examples when I teach, I would give examples when I hold meetings with people, I would talk about it with colleagues, what did you watch yester night? How did you like Makutano Junction? (Nick, personal communication, 2013).

Most participants discovered that the programme was of essence to them and unconsciously they had applied what they learnt in the programme whatsoever. The participants commented on the characters' behaviour and actions and these comments worked for both good model characters and bad model characters. Participants had mixed reactions on Bernadette who is a lead role. Some criticized Bernadette for being over reactive, obsessive and deceptive while others praised her for her courage and ability to make things happen. Lorah sharply criticizes Bernadette for her spiky approach to issues:

Benadette looks like she is very rowdy. Her tone of communication discourages but if she could tone down and try to educate masses gently and allow them to participate, it could be better. You know she takes things to be personal (Lorah, personal communication, 2013).

Bad model characters, like Snake and Doctor Penny are also criticized for appearing inhuman, strongly undesirable and exaggeratingly crafty, selfish and arrogant.

On the other hand, some participants were identified as good role model characters in society like Doctor Charles, the chief and Maspeedy. This was in relation to their services to the community.

I am concerned about the medical services they offer. The services are poor because I have witnessed people struggling and suffering. While Doctor Charles is working to bring things in order he is being pulled down by Doctor Penny; a corrupt and reluctant doctor. She takes bribes for services (FGD responded 6: a 26-year-old house wife)
On general the participants faulted and also praised the Makutano Community in reference on how they handled issues that affected them. They also noted that the programme has a lot of strength by its nature of educating, entertaining and informing the audience on current issues especially on voting (data collection for this study took place immediately after the voting exercise).

it has a lot of strengths and you know somebody can sit down, watch that programme while you are resting your mind from the hustles and bustles of the day also to get information (Emmah, personal communication, 2013).

\section{CONCLUSION}

This paper sought to determine whether the plotlines in the $M J$ drama Series especially of socioeconomic and political issues enhanced participation of audience. The study established that participants desired to understand their role as citizens and their commitment to avoid over dependence on government hence the need to watch the educative drama Series. As further highlighted, the participants believed that the choice to learn from the drama should be at individual level depending on one's gratifications. However, it was clear that the participants felt the lack of external motivation due to lack of awareness which led to casual intake of TV drama messages by the audience.

In essence, the viewers believed that the programme is a catalyst to fostering grassroots interactions that would lead to community mobilization that would bring about behaviour change. They strongly conclude that the drama is a perfect medium through which viewers can address their socio-economic and political challenges.

\section{RECOMMENDATIONS}

On assessing the viewer involvement and use of the story content with emphasis on the theme of citizenship, the study recommends use of other audience reception processes to establish the effect of the programme to the audience. For instance, the results of this study do not provide insights why some story elements or characteristics were perceived in a particular manner that the participants revealed. These insights would be useful for the development of EE storylines. Thus, future research in EE should focus on the individual viewer's processes and story elements that account for positive or negative evaluations of dimensions of perceived realism.

\section{REFERENCES}

1. Maslamani L. Education and Digital Citizenship: A Proposed Vision. Education World Journal. 2014; 47(2), 17-94.

2. Mwangi C. Media Influence on Public Policy in Kenya: The Case of Illicit Brew Consumption. 
SAGE Open, April-June 2018, 1-13.

3. Heather D. 2013. What is citizenship? http://www.wiley.com

4. Street J, Inthorn S, Scott M. Playing at politics? Popular culture as political engagement. Parliamentary Affairs. 2012 Apr 1;65(2):338-58.

5. Flanagan C, Finlay A, Gallay L, Kim T. Political incorporation and the protracted transition to adulthood: The need for new institutional inventions. Parliamentary affairs. 2012 Jan 1;65(1):29-46.

6. Benequista, N. A Summary of Findings from a Decade of Collaborative Research on Citizen Engagement: Blurring the Boundaries of Citizen Action across States and Societies.2011; Citizenship DRC. From www.drc-citizenship.org.

7. Gaventa J, Barrett G. So what difference does it make? Mapping the outcomes of citizen engagement. IDS Working Papers. 2010 Oct;2010(347):01-72.

8. Bowen $H$. Information at the Grassroots: Analyzing the media use and communication habits of Kenyans to support effective development. Africa Development Research Series, available at: http://www. audiencescapes. org/africa-research-survey-quantitative-analysisghanakenya. 2010.

9. Hope KR. Managing the public sector in Kenya: reform and transformation for improved performance. Journal of Public Administration and Governance. 2012;2(4):128-43.

10. Bowry P. Simplifying the language used by lawyers. Standard News; 2015.

11. Njogu K. Role of language in building inclusive Kenya. Saturday Nation Newspaper; 2017.

12. Brown WJ, Singhal A. Entertainment-education media strategies for social change: Promises and problems. Mass media social control and social. 1999:263-80.
13. Munga J. Kenyans for Change; The second Republic of Kenya: what is my role? Available online http:epaper. 2010. The Kenyan monitor.com accessed on 11/01/2012.

14. Martens H, Hobbs R. How media literacy supports civic engagement in a digital age. Atlantic Journal of Communication. 2015 Mar 15;23(2):120-37.

15. Musila PM. Effects of motivational practices and pupils performance in K.C.P.E in public primary schools in central division Machakos district. (MED thesis) university of Nairobi; 2010.

16. Bandura A. Self-efficacy: The exercise of control. New York: W.H. Freeman; 1997.

17. Weinstein CE. Fostering learning autonomy through the use of learning strategies. Journal of reading. 1987 Apr 1;30(7):590-5.

18. Nabavi RT. Bandura's Social Learning Theory \& Social Cognitive Learning Theory. 2014. https://www.researchgate.net/publication/2677502 $\underline{04}$

19. Bryman A. Integrating quantitative and qualitative research: how is it done?. Qualitative research. 2006 Feb;6(1):97-113.

20. Hesse B, Sharlene N. Mixed Methods Research: Merging Theory with Practice.

21. Ivankova NV, Creswell JW, Stick SL. Using mixed-methods sequential explanatory design: From theory to practice. Field methods. 2006 Feb;18(1):3-20.

22. Creswell JW. Research design: Qualitative, quantitative and mixed methods approach. Thousand Oaks, CA: Sage Publications; 2003.

23. Castillo R. Who is Slovin and where and how did the Slovin's Formula for determining the sample size for a survey research originated?; 2017.

24. Sood S. Audience involvement and entertainment - education. Communication theory. 2002 May;12(2):153-72. 